\title{
Studi Perbandingan antara Integrally Stiffened Plate (Combo Plate) dengan Pelat Berpenegar Konvensional pada Geladak
}

\author{
Uun Kusnul Khotimah, Achmad Zubaydi , Totok Yulianto \\ Departemen Teknik Perkapalan, Fakultas Teknologi Kelautan \\ Institut Teknologi Sepuluh Nopember (ITS) 60111 Indonesia \\ e-mail: zubaydi@na.its.ac.id; totoky@na.its.ac.id
}

\begin{abstract}
Abstrak-Combo plate merupakan produk dari perkembangan teknologi dalam bidang konstruksi aerospace. Keuntungan jenis pelat tersebut adalah mampu menghemat biaya dan mempercepat waktu produksi . Tujuan dalam penelitian ini adalah mengetahui perbandingan kekuatan combo plate dengan pelat berpenegar konvensional meliputi continuous weld, chain weld dan staggered weld bila digunakan dalam konstruksi kapal. Perbandingan dilakukan dengan membandingkan nilai tegangan dari 3 variasi beban (lateral, bending dan puntir) dan 3 variasi besar beban. Adapun model yang digunakan dalam penelitian ini ada 4 yaitu combo plate, continuous weld, chain weld dan staggered weld. Pada variasi pelat berpenegar konvensional dilakukan perbandingan tegangan sisa menggunakan metode elemen hingga. Hasil akhir yang didapat adalah combo plate memiliki tegangan paling kecil pada beban lateral yaitu saat beban $1000 \mathrm{~N} / \mathrm{m}^{2}$ tegangan terbesar bernilai 66.03 MPa, beban tekan $2000 \mathrm{~N} / \mathrm{m}^{2}$ menghasilkan nilai tegangan terbesar 132.07 MPa dan pada beban $3500 \mathrm{~N} / \mathrm{m}^{2}$ menghasilkan tegangan terbesar 231.13 MPa sementara pada momen bending dan puntir memiliki tegangan paling besar dibanding dengan pelat berpenegar konvensional. Untuk nilai tegangan sisa paling besar adalah continous weld sebesar 90.05 Mpa.
\end{abstract}

Kata Kunci-Combo Plate, Continous Weld, Chain Weld,Staggered Weld, Tegangan, Tegangan Sisa, Metode Elemen Hingga.

\section{PENDAHULUAN}

K ebutuhan sektor industri akan efektifitas dan efisiensi dalam menyelesaikan pekerjaan memicu adanya perkembangan teknologi. Teknologi akan terus berkembang seiring dengan berjalannya waktu, hal ini tidak lepas dari perkembangan proses manufaktur. Dalam bidang industri adanya teknologi produksi sangat membantu dari segi efektifitas kerja dan efisiensi biaya. Salah satu contoh hasil perkembangan teknologi adalah teknik penyambungan logam. Awalnya penyambungan logam dilakukan dengan metode keling kemudian berkembang dengan metode yang lebih canggih yaitu pengelasan.

Dewasa ini metode pengelasan sudah diterapkan dalam dunia industri manufaktur terutama yang memanfaatkan logam sebagai bahan baku utamanya. Contoh penerapan metode pengelasan adalah pada industri pesawat luar angkasa. Pembuatan pesawat luar angkasa menggunakan material yang bersifat ringan yaitu alumunium. Material alumunium memiliki sifat yang kurang baik dibandingkan dengan baja saat dilas. Sehingga untuk mengatasi hal tersebut pengelasan alumunium harus dilakukan dengan alat dan teknik yang tepat dan tentunya berpengaruh pada biaya produksi. Produsen akan mencari solusi agar biaya dapat dikurangi tanpa menurunkan kualitas. Atas dasar inilah akhirnya ilmuwan NASA melakukan kajian dan penelitian mengenai "Integrally Stiffened" struktur dalam upaya mengurangi biaya produksi tanpa mengurangi performa struktur. Pada mulanya pembuatan integrally stiffened plate (combo plate) dilakukan dengan mesin bubut seiring dengan berkembangnya teknologi muncul teknik ekstrusi.

Pembuatan combo plate dengan metode ekstrusi mampu menghasilkan produk lebih cepat dibanding mesin bubut sehingga menghemat waktu. Combo plate yang memiliki kelebihan yaitu memiliki bagian yang lebih sedikit dibanding pelat berpenagar konvensional. Pemanfaatan combo plate sendiri banyak diterapkan untuk bidang aerospace, sekarang industri perkapalan terutama kapal alumunium mulai menggunakan jenis pelat ini. Penggunaan integrally stiffened plate atau combo plate pada konstruksi kapal perlu dilakukan analisa perbandingan kekuatan dengan pelat berpenegar konvensional.

Oleh karena itu dilakukan penelitian tentang perbandingan kekuatan combo plate dengan pelat berpenegar konvensional. Pembandingan dilakukan dengan metode elemen hingga menggunakan 4 variasi model, 3 variasi jenis beban dan 3 variasi harga beban.

\section{STUDI LITERATUR}

\section{A. Integrally Stiffened Plate (Combo Plate)}

Integrally Stiffened Plate atau combo plate merupakan produk yang dikembangkan dalam bidang aerospace. Combo plate berupa pelat dan penegar yang saling terintegrasi tanpa disambungkan dengan las. Sebelum ditemukan, pembuatan badan pesawat awalnya menggunakan pelat berpenegar konvensinal dimana pelat dan penegar disambungkan dengan metode keling. Struktur combo plate dirancang mampu menahan pada berbagai kondisi pembebanan serta mampu mempertahankan tingkat toleransi kerusakan yang ditentukan. Salah satu keuntungan combo plate adalah penghematan dari segi berat, biaya dan proses produksi[1].

\section{B. Metode Elemen Hingga}

Metode elemen hingga menurut adalah metode numerik yang digunakan dalam meyelesaikan permasalahan di bidang matematika dan fisika meliputi geometri, pembebanan dan sifat-sifat dari material yang sangat rumit. Selain itu disebut metode ini digunakan untuk menyelesaikan masalah seperti analisis struktural, thermal, aliran fluida dan elektromagnetik. Metode ini merupakan metode pendekatan untuk seluruh masalah yang kompleks seperti variasi bentuk, kondisi batas, dan beban. Pendekatan metode elemen hingga yaitu menggunakan informasi pada titik simpul (node). 
Dalam proses penentuan node disebut dengan pendeskritan (discretization), suatu sistem dibagi menjadi elemen-elemen yang lebih kecil kemudian penyelesaian masalah dilakukan pada bagian-bagian tersebut dan digabung kembali sehingga diperoleh solusi secara menyeluruh[2].

Pada bidang perkapalan metode elemen hingga digunakan untuk menganalisis kekuatan konstruksi wing tank kapal dalam studi kasus kapal tanker 17500 LTDW dengan memvariasikan jenis profil[3]. Selain untuk analisis konstruksi wing tank, metode elemen hingga dapat digunakan dalam menganalisis sekat bergelombang untuk mengetahui tegangan dan deformasi pada sekat yang menggunakan konstruksi tambahan berupa lower stool dan diafragma sekat[4].

\section{Tegangan dan Regangan}

Tegangan merupakan gaya yang bekerja pada luasan kecil yang tak terhingga pada potongan penampang, maka akan terdiri dari bermacam-macam besaran dan arah. Intensitas gaya yang bekerja pada luasan berubah-ubah dari suatu titik ke titik lain, arah intensitas gaya miring terhadap bidang. Sedangkan intensitas gaya yang tegak lurus dengan bidang disebut tegangan normal (normal stress)[5]. Besar nilai tegangan dirumuskan dalam Persamaan 1

$$
\text { Stress }(\sigma)=\frac{\text { Force }}{\text { Cross Sectional Area }}=\frac{\mathrm{F}}{\mathrm{A}}
$$

Regangan merupakan respon dari benda saat diberi beban. Regangan didefinisikan sebagai perubahan panjang material dibagi panjang awal akibat gaya yang diberikan pada material. Besar tegangan dirumuskan dalam Persamaan 2

$$
\text { Strain }(\varepsilon)=\frac{\text { Elongation }}{\text { Original Length }}=\frac{\Delta L}{\text { Lo }}
$$

\section{Pengelasan}

Proses pengelasan dimulai dari proses penyambungan logam yang sudah ada sebelum era revolusi industri yaitu dengan cara membuat cetakan berbahan pasir diatas pelat logam dan mengisinya dengan logam cair. Cetakan ini dapat dibentuk sesuai dengan bentuk yang diiinginkan. Selain itu, proses penyambungan juga dilakukan dengan menyambung dua pelat logam dengan logam cair. Pada akhir abad ke-19, cara-cara dan teknik pengelasan mulai berkembang pesat yaitu dengan menggunakan energi listrik dan berkembang hingga sekarang[6].

Salah satu contoh penerapan pengelasan dalam bidang industri perkapalan adalah pengelasan pada flange pipa. Variasi sambungan las yang digunakan pada flange pipa dapat berupa socket-weld atau butt-weld[7].

\section{E. Tegangan Sisa}

Pada proses pengelasan akan menimbulkan tegangan sisa hal ini disebabkan adanya perubahan temperatur non-uniform pada material. Dalam masalah pengelasan, tegangan sisa yang akan ditinjau adalah tegangan sisa yang ditimbulkan dari distribusi regangan non-elastik yang tidak merata pada material. Tegangan sisa pada logam dapat terjadi karena banyak hal selama proses produksi.

Faktor-faktoryang mempengaruhi pembentukan tegangan sisa adalah batas transformasi dan batas luluh beban, temperatur pemanasan tertinggi, kecepatan pendinginan, tahanan luar dan pemanasan awal. Ketika material dipanaskan secara merata akan terjadi tegangan. Tegangan sisa juga akan terjadi ketika regangan yang didistribusikan tidak merata seperti regangan plastis[6].
Tegangan sisa dalam konstruksi kapal salah satunya dapat ditemui pada stopper yang digunakan untuk mengekang pelat saat pengelasan, semakin panjang ukuran stopper maka tegangan sisa makin kecil[8]. Penggunaan stopper dapat mengurangi deformasi pada material, namun apabila penggunaan jumlah stopper yang berlebihan juga akan memperbesar tegangan sisa[9].

\section{METODOLOGI}

\section{A. Pemodelan}

Dalam pengerjaan Tugas Akhir analisis diawali dengan pembuatan model combo plate dan pelat berpenegar konvensional yang meliputi continous weld, chain weld dan staggered weld dengan menggunakan software metode elemen hingga. Analisis dilakukan dengan dengan 2 cara yaitu analisis thermal dan structural.

\section{B. Analisis Structural Model}

Analisis ini dilakukan untuk mengetahui nilai tegangan dan deformasi dari 4 variasi model dengan pemberian 3 jenis beban (tekan, momen bending dan momen puntir) dan 3 variasi harga beban. Adapun tahapannya sebagai berikut :

\section{1) Pembuatan geometri}

Geometri pada model dilakukan dengan menggunakan sketsa (sketch). Karena model yang dibuat lebih sederhana, maka hal pertama yang dibuat adalah sketsa pelat $1500 \mathrm{x}$ $6000 \mathrm{~mm}$. Kemudian dibuat kampuh las dan selanjutnya adalah profil T berukuran 70x5 / 40x6.

\section{2) Uji Konvergensi}

Uji konvergensi adalah salah satu cara dalam menentukan ukuran elemen yang tepat dalam pembuatan model elemen hingga sehingga model dapat menghasilkan nilai yang valid. Konvergensi dilakukan dengan cara membandingkan beberapa hasil pemodelan dengan ukuran elemen berbeda. Data yang digunakan sebagai acuan dalam melakukan uji konvergensi adalah hasil uji tegangan. Hasil dapat dinyatakan valid dan dapat dijadikan acuan apabila hasil dari pengujian menunjukkan hasil yang tidak signifikan dan kurang dari dua persen $(<2 \%)$.

\section{3) Meshing}

Proses ini adalah proses membagi keseluruhan sistem ke dalam elemen-elemen kecil yang seragam dengan tujuan agar analisis menjadi semakin detail pada keseluruhan sistem tersebut. Sizing dilakukan untuk menentukan ukuran dari elemen yang akan digunakan.

\section{4) Penentuan Constraint}

Pemberian tumpuan ini berguna agar proses perhitungan dapat dilakukan. Jika model tidak diberi tumpuan maka gaya reaksi akan sangat besar sehingga tidak sesuai dengan kondisi sebenarnya. Tumpuan dalam pemodelan diberikan pada daerah yang dianggap tidak bergerak.

\section{5) Memasukkan Beban}

Pemberian beban berguna agar proses perhitungan dapat dilakukan. Adapun jenis beban yang digunakan ada tiga yaitu tekan, momen bending dan momen puntir. Dalam analisis tegangan sisa beban yang diberikan adalah beban thermal. Untuk harga beban yang diberikan untuk beban tekan yaitu $1000 \mathrm{~Pa}, 2000 \mathrm{~Pa}$ dan $3500 \mathrm{~Pa}$. Sementara untuk beban momen yaitu $100 \mathrm{Nm}, 200 \mathrm{Nm}$ dan $350 \mathrm{Nm}$. Selain itu pemberian beban dilakukan pada satu titik yang telah ditentukan. 
6) Running Program

Proses analisis yang dilakukan oleh program dimana akan menghasilkan output berupa tegangan dan deformasi.

\section{Pembebanan}

Pada analisis ini dilakukan pembebanan jenis beban lateral, momen bending dan momen puntir. Adapun titik pembebanan dan pengamatan tegangan dilakukan seperti pada Gambar 1

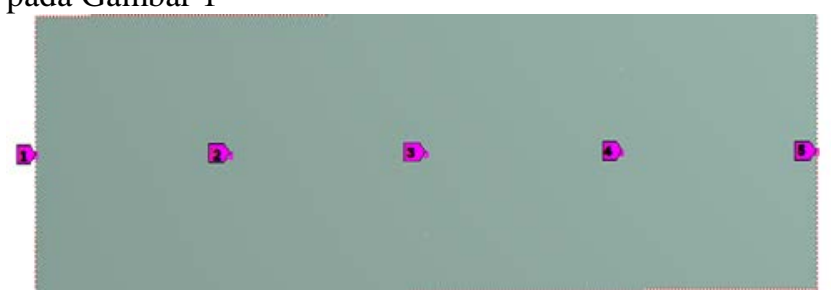

Gambar 1. Lokasi Pembebanan dan Pengamatan Tegangan

\section{HASIL DAN PEMBAHASAN}

\section{A. Variasi Jenis Beban I - Latreal}

Dari hasil yang dilakukan dari jenis beban lateral pada setiap jenis model dengan software elemen hingga didapat hasi seperti pada Tabel 1, 2 dan 3

Tabel 1.

Tegangan Pada Beban 1000 N/m²

\begin{tabular}{cccccc}
\hline \hline Titik & $\begin{array}{c}\text { Combo } \\
\text { Plate }\end{array}$ & $\begin{array}{c}\text { Continous } \\
\text { Weld }\end{array}$ & $\begin{array}{c}\text { Chain } \\
\text { Weld }\end{array}$ & $\begin{array}{c}\text { Staggered } \\
\text { Weld }\end{array}$ & Satuan \\
\hline 1 & 0 & 0 & 0 & 0 & \\
2 & 64.73 & 80.82 & 79.05 & 79.05 & Mpa \\
3 & 66.03 & 82.13 & 80.42 & 80.42 & \\
4 & 64.73 & 80.82 & 79.05 & 79.05 & \\
5 & 0 & 0 & 0 & 0 & \\
\hline \hline
\end{tabular}

Tabel 2.

Tegangan Pada Beban 2000 N/m²

\begin{tabular}{cccccc}
\hline \hline Titik & $\begin{array}{c}\text { Combo } \\
\text { Plate }\end{array}$ & $\begin{array}{c}\text { Continous } \\
\text { Weld }\end{array}$ & $\begin{array}{c}\text { Chain } \\
\text { Weld }\end{array}$ & $\begin{array}{c}\text { Staggered } \\
\text { Weld }\end{array}$ & Satuan \\
\hline 1 & 0 & 0 & 0 & 0 & \\
2 & 129.47 & 161.66 & 158.17 & 158.17 & \\
3 & 132.07 & 164.27 & 160.84 & 160.84 & Mpa \\
4 & 129.47 & 161.66 & 158.17 & 158.17 & \\
5 & 0 & 0 & 0 & 0 & \\
\hline \hline
\end{tabular}

Tabel 3.

Tegangan Pada Beban 3500 N/m²

\begin{tabular}{cccccc}
\hline \hline Titik & $\begin{array}{c}\text { Combo } \\
\text { Plate }\end{array}$ & $\begin{array}{c}\text { Continous } \\
\text { Weld }\end{array}$ & $\begin{array}{c}\text { Chain } \\
\text { Weld }\end{array}$ & $\begin{array}{c}\text { Staggered } \\
\text { Weld }\end{array}$ & Satuan \\
\hline 1 & 0 & 0 & 0 & 0 & \\
2 & 226.58 & 282.9 & 276.68 & 276.68 & \\
3 & 231.13 & 287.48 & 281.47 & 281.47 & Mpa \\
4 & 226.58 & 282.9 & 276.68 & 276.68 & \\
5 & 0 & 0 & 0 & 0 & \\
\hline \hline
\end{tabular}

Untuk perbandingan tegangan dapat dilihat pada Gambar 2,3dan 4

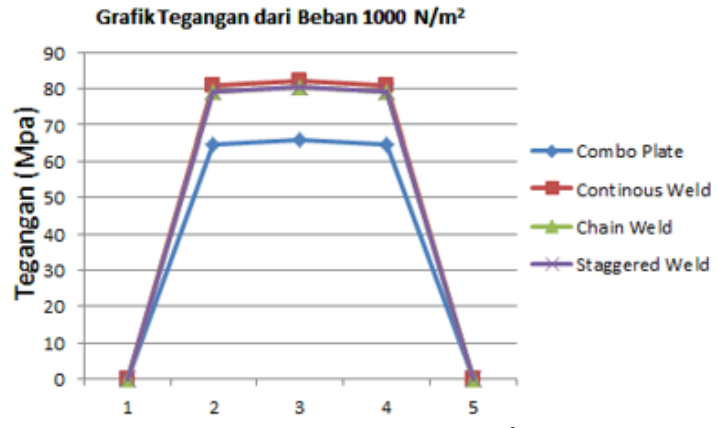

Gambar 2. Grafik Tegangan pada Beban 1000 N/m²
Pada Gambar 2 Tegangan terbesar combo plate bernilai 66.03 MPa dan nilai tegangan minimum $0 \mathrm{MPa}$. Model pelat berpenegar konvensional continous weld tegangan terbesar bernilai $82.13 \mathrm{MPa}$ dan nilai tegangan minimum $0 \mathrm{MPa}$. Chain weld memiliki tegangan terbesar $80.42 \mathrm{MPa}$ dan tegangan minimum 0 MPa. Staggered weld memiliki tegangan terbesar 80.42 dan tegangan minimum $0 \mathrm{MPa}$.

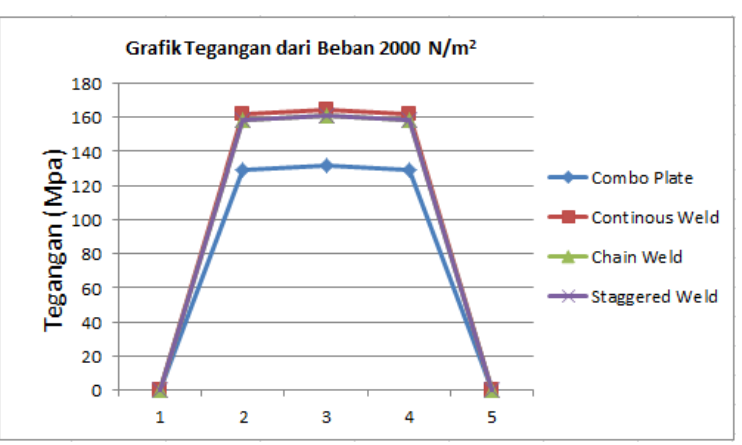

Gambar 3. Grafik Tegangan pada Beban 2000 N/m²

Pada Gambar 3 Tegangan terbesar combo plate bernilai 132.07 MPa dan nilai tegangan minimum $0 \mathrm{MPa}$. Model pelat berpenegar konvensional continous weld tegangan terbesar bernilai 164.27 MPa dan nilai tegangan minimum 0 MPa. Chain weld memiliki tegangan terbesar $160.84 \mathrm{MPa}$ dan tegangan minimum 0 MPa. Staggered weld memiliki tegangan terbesar $160.84 \mathrm{MPa}$ dan tegangan minimum 0 MPa.

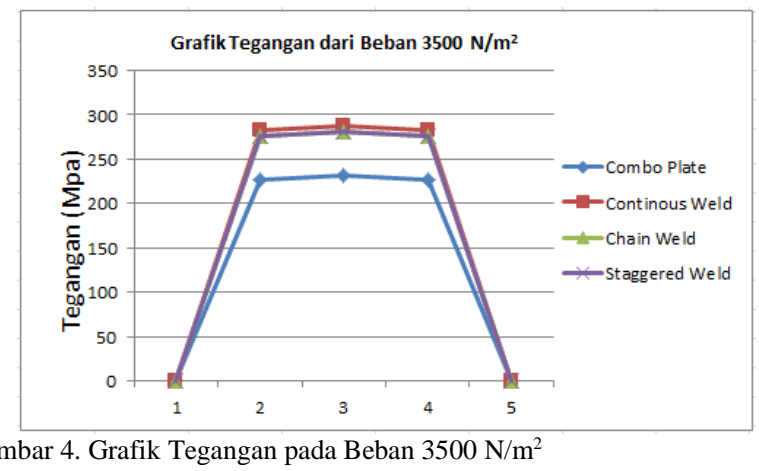

Pada Gambar 4 Tegangan terbesar combo plate bernilai 231.13 MPa dan nilai tegangan minimum 0 MPa. Model pelat berpenegar konvensional continous weld tegangan terbesar bernilai $287.48 \mathrm{MPa}$ dan nilai tegangan minimum 0 MPa. Chain weld memiliki tegangan terbesar 281.47 MPa dan tegangan minimum $0 \mathrm{MPa}$. Staggered weld memiliki tegangan terbesar $281.47 \mathrm{MPa}$ dan tegangan minimum 0 MPa.

Dari ketiga grafik terlihat combo plate memiliki tegangan dari beban lateral yang lebih keci dibanding pelat berpenegar konvensional (continous weld, chain weld dan staggered weld) hal ini dikarenakan combo plate memiliki nilai kekakuan yang lebih besar sehingga tegangan beban lateral memiliki tegangan yang kecil.

\section{B. Variasi Jenis Beban I - Momen Bending}

Dari hasil yang dilakukan dari jenis beban momen bending dengan software elemen hingga didapat hasil seperti pada Tabel 4, 5 dan 6.

Tabel 4.

Tegangan Pada Beban 100 Nm

\begin{tabular}{cccccc}
\hline \hline Titik & $\begin{array}{c}\text { Combo } \\
\text { Plate }\end{array}$ & $\begin{array}{c}\text { Continous } \\
\text { Weld }\end{array}$ & $\begin{array}{c}\text { Chain } \\
\text { Weld }\end{array}$ & $\begin{array}{c}\text { Staggered } \\
\text { Weld }\end{array}$ & Satuan \\
\hline 1 & 22.07 & 18.4 & 18.64 & 18.64 & \multirow{2}{*}{ Mpa } \\
2 & 8.42 & 4.25 & 4.46 & 4.46 &
\end{tabular}




\begin{tabular}{ccccc}
3 & 6.79 & 2.95 & 2.97 & 2.97 \\
4 & 8.42 & 4.25 & 4.46 & 4.46 \\
5 & 22.07 & 18.4 & 18.64 & 18.64 \\
\hline \hline
\end{tabular}

Tabel 5.

Tegangan Pada Beban 200 Nm

\begin{tabular}{cccccc}
\hline \hline Titik & $\begin{array}{c}\text { Combo } \\
\text { Plate }\end{array}$ & $\begin{array}{c}\text { Continous } \\
\text { Weld }\end{array}$ & $\begin{array}{c}\text { Chain } \\
\text { Weld }\end{array}$ & $\begin{array}{c}\text { Staggered } \\
\text { Weld }\end{array}$ & Satuan \\
\hline 1 & 22.07 & 18.4 & 18.64 & 18.64 & \\
2 & 8.42 & 4.25 & 4.46 & 4.46 & \\
3 & 6.79 & 2.95 & 2.97 & 2.97 & Mpa \\
4 & 8.42 & 4.25 & 4.46 & 4.46 & \\
5 & 22.07 & 18.4 & 18.64 & 18.64 & \\
\hline \hline
\end{tabular}

Tabel 6.

Tegangan Pada Beban $350 \mathrm{Nm}$

\begin{tabular}{cccccc}
\hline \hline Titik & $\begin{array}{c}\text { Combo } \\
\text { Plate }\end{array}$ & $\begin{array}{c}\text { Continous } \\
\text { Weld }\end{array}$ & $\begin{array}{c}\text { Chain } \\
\text { Weld }\end{array}$ & $\begin{array}{c}\text { Staggered } \\
\text { Weld }\end{array}$ & Satuan \\
\hline 1 & 77.27 & 64.62 & 65.24 & 65.24 & Mpa \\
2 & 29.47 & 14.89 & 15.61 & 15.61 & \\
3 & 23.77 & 10.32 & 10.41 & 10.41 & \\
4 & 29.47 & 14.89 & 15.61 & 15.61 & \\
5 & 77.27 & 64.62 & 65.24 & 65.24 & \\
\hline \hline
\end{tabular}

Untuk perbandingan tegangan dapat dilihat pada Gambar 5,6dan 7

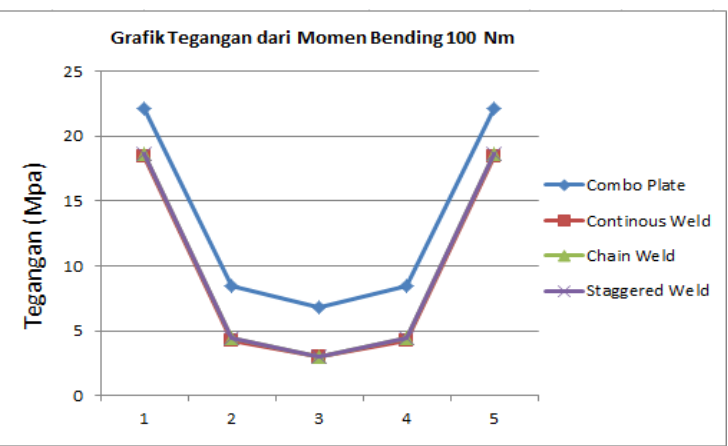

Gambar 5. Grafik Tegangan pada Beban 100 Nm

Pada Gambar 5 Tegangan terbesar combo plate bernilai 22.07 MPa dan nilai tegangan minimum 6.79 MPa. Model pelat berpenegar konvensional continous weld tegangan terbesar bernilai 18.4 MPa dan nilai tegangan minimum 2.95 $\mathrm{MPa}$. Chain weld memiliki tegangan terbesar 18.64 MPa dan tegangan minimum 2.97 MPa. Staggered weld memiliki tegangan terbesar 18.64 MPa dan tegangan minimum 2.97 MPa.

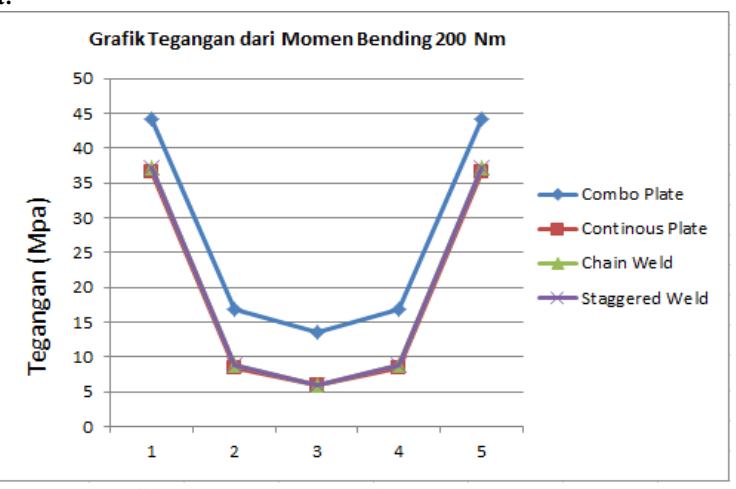

Gambar 6 Grafik Tegangan pada Beban 200 Nm

Pada Gambar 6 Tegangan terbesar combo plate bernilai 44.15 MPa dan nilai tegangan minimum 13.58 MPa. Model pelat berpenegar konvensional continous weld tegangan terbesar bernilai 36.64 MPa dan nilai tegangan minimum 5.89 $\mathrm{MPa}$. Chain weld memiliki tegangan terbesar 37.28 MPa dan tegangan minimum $5.94 \mathrm{MPa}$. Staggered weld memiliki tegangan terbesar 37.28 MPa dan tegangan minimum 5.94 MPa.

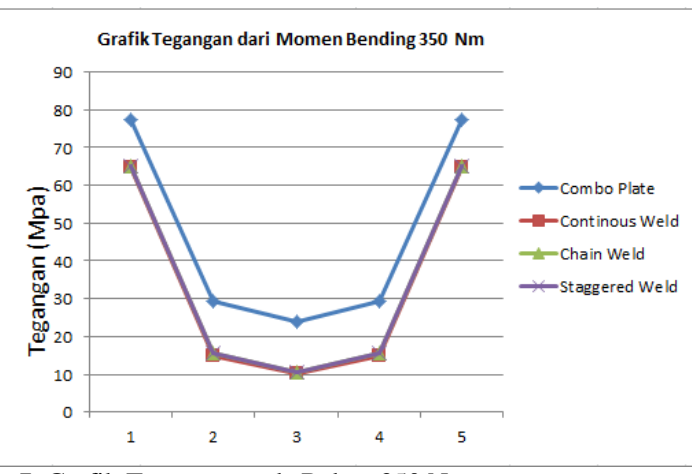

Gambar 7. Grafik Tegangan pada Beban $350 \mathrm{Nm}$

Pada Gambar 7 Tegangan terbesar combo plate bernilai 77.27 MPa dan nilai tegangan minimum 23.77 MPa. Model pelat berpenegar konvensional continous weld tegangan terbesar bernilai 64.62 MPa dan nilai tegangan minimum 10.32 MPa. Chain weld memiliki tegangan terbesar 65.24 MPa dan tegangan minimum $10.41 \mathrm{MPa}$. Staggered weld memiliki tegangan terbesar 65.24 $\mathrm{MPa}$ dan tegangan minimum 10.41 MPa.

Dari ketiga grafik terlihat ketiga model pelat berpenegar konvensional memiliki tegangan yang lebih kecil dari model combo plate. Hal ini disebabkan karena tegangan akibat beban momen bekerja tegak lurus dengan luas penampang dengan nilai tegangan berbanding terbalik dengan besar luas penampang. Pada pelat berpenegar konvensional memiliki luas penampang yang lebih besar karena adanya penambahan luas dari model las sehingga nilai tegangan lebih kecil dibanding tegangan pada combo plate.

\section{Variasi Jenis Beban I-Momen Puntir}

Dari hasil yang dilakukan dari jenis beban momen puntir dengan software elemen hingga didapat hasil seperti pada Tabel 7, 8 dan 9.

Tabel 7.

Tegangan Pada Beban 100 Nm

\begin{tabular}{cccccc}
\hline \hline Titik & $\begin{array}{c}\text { Combo } \\
\text { Plate }\end{array}$ & $\begin{array}{c}\text { Continous } \\
\text { Weld }\end{array}$ & $\begin{array}{c}\text { Chain } \\
\text { Weld }\end{array}$ & $\begin{array}{c}\text { Staggered } \\
\text { Weld }\end{array}$ & Satuan \\
\hline 1 & 25.86 & 19.32 & 19.7 & 19.7 & \\
2 & 15.89 & 9.3 & 9.73 & 9.73 & \\
3 & 13.27 & 6.84 & 7.11 & 7.11 & Mpa \\
4 & 15.89 & 9.3 & 9.73 & 9.73 & \\
5 & 25.86 & 19.32 & 19.7 & 19.7 & \\
\hline \hline
\end{tabular}

Tabel 8.

Tegangan Pada Beban 200 Nm

\begin{tabular}{cccccc}
\hline \hline Titik & $\begin{array}{c}\text { Combo } \\
\text { Plate }\end{array}$ & $\begin{array}{c}\text { Continous } \\
\text { Weld }\end{array}$ & $\begin{array}{c}\text { Chain } \\
\text { Weld }\end{array}$ & $\begin{array}{c}\text { Staggered } \\
\text { Weld }\end{array}$ & Satuan \\
\hline 1 & 51.73 & 38.64 & 39.4 & 39.4 & \\
2 & 31.78 & 18.61 & 19.37 & 19.37 & \\
3 & 26.54 & 13.68 & 14.23 & 14.23 & Mpa \\
4 & 31.78 & 18.61 & 19.37 & 19.37 & \\
5 & 51.73 & 38.64 & 39.4 & 39.4 & \\
\hline \hline
\end{tabular}

Tabel 9.

Tegangan Pada Beban 350 Nm

\begin{tabular}{cccccc}
\hline \hline Titik & $\begin{array}{c}\text { Combo } \\
\text { Plate }\end{array}$ & $\begin{array}{c}\text { Continous } \\
\text { Weld }\end{array}$ & $\begin{array}{c}\text { Chain } \\
\text { Weld }\end{array}$ & $\begin{array}{c}\text { Staggered } \\
\text { Weld }\end{array}$ & Satuan \\
\hline 1 & 90.53 & 68.52 & 68.95 & 68.95 & \\
2 & 55.62 & 33.88 & 34.06 & 34.06 & \\
3 & 46.44 & 24.54 & 24.91 & 24.91 & Mpa \\
4 & 55.62 & 33.88 & 34.06 & 34.06 & \\
5 & 90.53 & 68.52 & 68.95 & 68.95 & \\
\hline \hline
\end{tabular}


Untuk perbandingan tegangan dapat dilihat pada Gambar 8,9dan 10

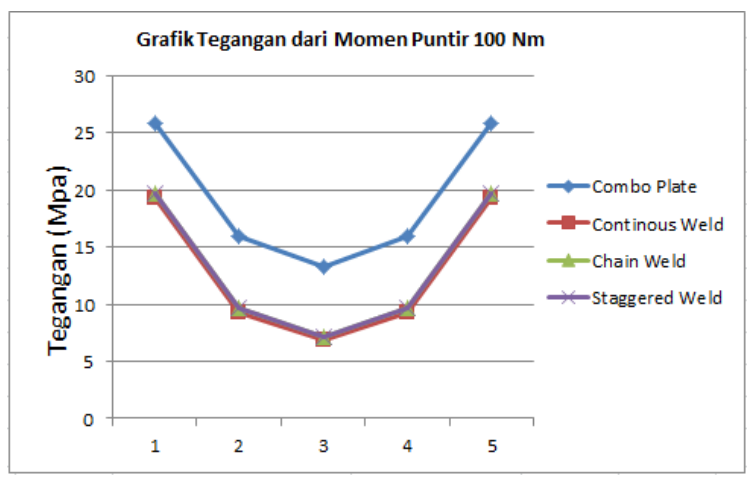

Gambar 8. Grafik Tegangan pada Beban 100 Nm

Pada Gambar 8 Tegangan terbesar combo plate bernilai 25.86 MPa dan nilai tegangan minimum 13.27 MPa. Model pelat berpenegar konvensional continous weld tegangan terbesar bernilai $19.32 \mathrm{MPa}$ dan nilai tegangan minimum 6.84 MPa. Chain weld memiliki tegangan terbesar 19.7 MPa dan tegangan minimum 7.11 MPa. Staggered weld memiliki tegangan terbesar 19.7 MPa dan tegangan minimum 7.11 MPa.

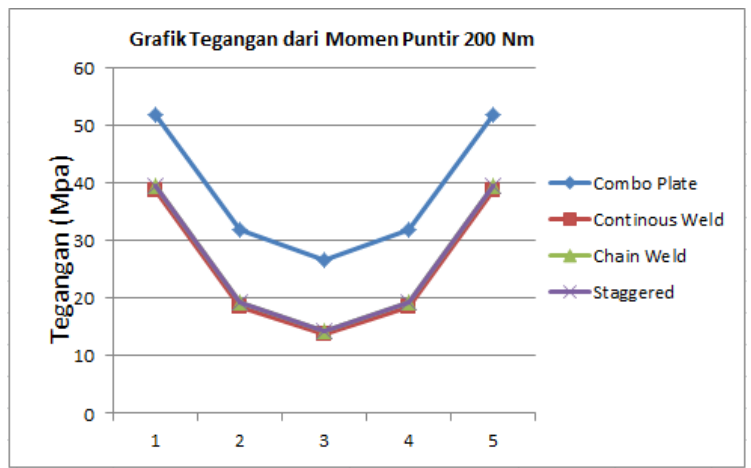

Gambar 9. Grafik Tegangan pada Beban 200 Nm

Pada Gambar 9 Tegangan terbesar combo plate bernilai 51.73 MPa dan nilai tegangan minimum 26.54 MPa. Model pelat berpenegar konvensional continous weld tegangan terbesar bernilai $38.64 \mathrm{MPa}$ dan nilai tegangan minimum 13.68 MPa. Chain weld memiliki tegangan terbesar 39.4 MPa dan tegangan minimum 14.23 MPa. Staggered weld memiliki tegangan terbesar 39.4 MPa dan tegangan minimum 14.23 MPa.

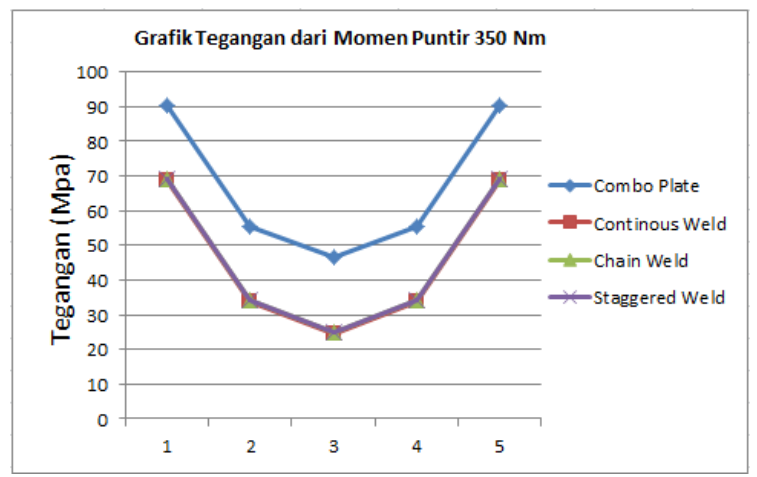

Gambar 10. Grafik Tegangan pada Beban 350 Nm

Pada Gambar 10 Tegangan terbesar combo plate bernilai 90.53 MPa dan nilai tegangan minimum 46.44 MPa. Model pelat berpenegar konvensional continous weld tegangan terbesar bernilai $68.52 \mathrm{MPa}$ dan nilai tegangan minimum $24.54 \mathrm{MPa}$. Chain weld memiliki tegangan terbesar 68.95 $\mathrm{MPa}$ dan tegangan minimum 24.91 MPa. Staggered weld memiliki tegangan terbesar $68.95 \mathrm{MPa}$ dan tegangan minimum 24.91 MPa.

Dari ketiga grafik terlihat ketiga model pelat berpenegar konvensional memiliki tegangan yang lebih kecil dari model combo plate. Hal ini disebabkan karena tegangan akibat beban momen bekerja tegak lurus dengan luas penampang dengan nilai tegangan berbanding terbalik dengan besar luas penampang. Pada pelat berpenegar konvensional memiliki luas penampang yang lebih besar karena adanya penambahan luas dari model las sehingga nilai tegangan lebih kecil dibanding tegangan pada combo plate.

\section{Tegangan Sisa}

Dari hasil analisis yang dilakukan didapat hasil tegangan sisa seperti pada Tabel 10 dan Gambar 11

Tabel 10.

Tegangan Sisa Pada Variasi Pelat Berpenegar Konvensional

\begin{tabular}{|c|c|c|c|}
\hline Model & Suhu (C) & $\begin{array}{c}\text { Base Metal (titk 1) } \\
\sigma_{\text {tekan }}\end{array}$ & $\begin{array}{c}\text { Las (titik 2) } \\
\sigma_{\text {tarik }}\end{array}$ \\
\hline Continous Weld & 437.98 & -42.2 & 90.5 \\
\hline Chain Weld & 433.65 & -43.64 & 83.48 \\
\hline Staggered Weld & 433.65 & -43.64 & 83.48 \\
\hline
\end{tabular}

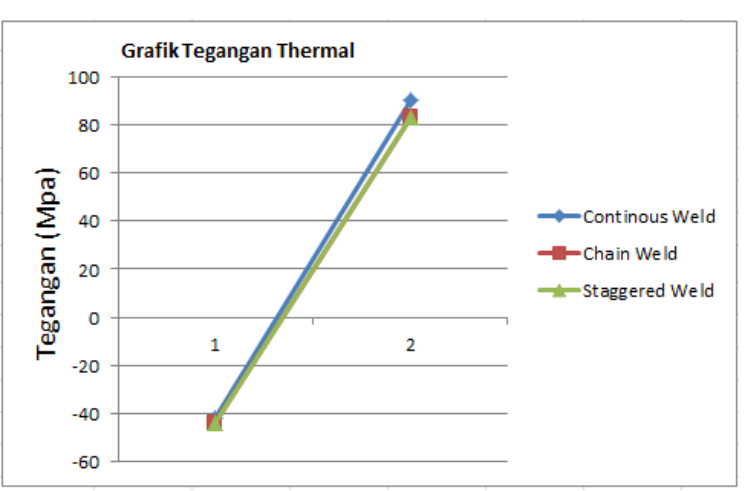

Gambar 11. Grafik Perbandingan Tegangan Sisa

Pada Gambar 11 didapat bahwa pada model continous weld memiliki nilai tegangan sisa terbesar $90.05 \mathrm{MPa}$. Model chain weld dan staggered weld memiliki tegangan sisa terbesar dengan nilai yang sama yaitu 83.48 $\mathrm{MPa}$.

\section{KESIMPULAN}

Perbandingan kekuatan yang dilakukan yaitu dengan membandingkan nilai tegangan antara combo plate dan pelat berpenegar konvensional. Combo plate memiliki nilai tegangan paling kecil dibandingkan pelat berpenegar konvensional pada jenis beban tekan. Saat beban $1000 \mathrm{~N} / \mathrm{m}^{2}$ tegangan terbesar bernilai 66.03 MPa, beban tekan 2000 $\mathrm{N} / \mathrm{m}^{2}$ menghasilkan nilai tegangan terbesar 132.07 MPa dan pada beban $3500 \mathrm{~N} / \mathrm{m}^{2}$ mengahasilkan tegangan terbesar 231.13 MPa. Sementara nilai tegangan akibat momen puntir dan momen bending memiliki nilai tegangan tertinggi dibanding pelat berpenegar konvensional.

Perbandingan tegangan sisa menghasilkan bahwa nilaitegangan sisa yang terbesar adalah pelat berpenegar konvensional yang dilas dengan jenis continous weld yaitu memiliki teganga sisa sebasar 90.05 MPa. Sementara combo plate tidak memiliki tegangan sisa karena tidak terdapat proses pengelasan atau pemanasan setempat.

Dalam penelitian ini masih banyak kekurangan sehingga untuk mendapatkan hasil yang lebih baik ada beberapa saran yang perlu dilakukan dan dikembangkan pada penelitian selanjutnya, yaitu : 
1. Perlu adanya eksperimen untuk memastikan perbandingan sebenarnya antara pelat berpenegar konvensional dengan combo plate karena pada pemodelan memiliki kendala yaitu sulit atau bahkan tidak bisa memodelkan pelat berpengar konvensional agar sesuai kondisi sebenarnya pada software.

2. Pada combo plate perlu dilakukan analisis pada bagian sambungan las antara dua atau lebih combo plate.

3. Perlu dilakukan analisis biaya pada pembangunan kapal alumunium menggunakan combo plate.

\section{DAFTAR PUSTAKA}

[1] D. Quinn, A. Murphy, and C. Glazebrook, “Aerospace stiffened panel initial sizing with novel skin sub-stiffening features,” Int. J. Struct. Stab. Dyn., vol. 12, no. 05, Oct. 2012.

[2] D. L. Logan, K. K. Chaudhry, and P. Singh, A first course in the finite element method, 4. ed. SI. Stamford CT: Cengage Learning, 2011.

[3] D. D. Sanjaya, S. H. Sujiatanti, and T. Yulianto, “Analisa kekuatan konstruksi wing tank kapal tanker menggunakan metode elemen hingga,” J. Tek. ITS, vol. 6, no. 2, pp. G277-G281, Sep. 2017.

[4] Z. Rabbani, A. Zubaydi, and S. H. Sujiatanti, “Analisa kekuatan sekat bergelombang kapal tanker menggunakan metode elemen hingga,” $J$. Tek. ITS, vol. 6, no. 2, pp. G282-G287, Sep. 2017.

[5] E. P. Popov, "Mechanics of Material 2nd edition,” Prentice-Hall, 1978. .

[6] T. Wiryosumarto, H. dan Okumura, Teknologi Pengelasan Logam. Jakarta: Pradnya Paramita, 1996.

[7] D. V. Dewangga and T. Yulianto, “Analisa pengaruh flange angle, toe radius, dan preparation angle terhadap deformasi dan tegangan sisa pada pengelasan butt joint dengan kampuh double $\mathrm{v}$ ganda menggunakan metode elemen hingga,” J. Tek. ITS, vol. 1, no. 1, pp. G40-G45, Sep. 2012.

[8] R. B. Putra and S. H. Sujiatanti, “Analisis pengaruh ukuran stopper pada sambungan pelat kapal terhadap tegangan sisa dan deformasi menggunakan metode elemen hingga,” J. Tek. ITS, vol. 6, no. 2, pp. G77-G81, Sep. 2017.

[9] A. A. Anggoro, "Analisis perbandingan pengaruh stopper model baut dengan konvensional terhadap tegangan sisa dan deformasi menggunakan metode elemen hingga,” Institut Teknologi Sepuluh Nopember, 2018. 